\title{
1 Bone disease in axial spondyloarthritis
}

2

3

4

5

6

7

8

9

Margot Van Mechelen ${ }^{1,2}$, Giulia Rossana Gulino ${ }^{1}$, Kurt de Vlam², Rik Lories ${ }^{1,2}$

${ }^{1}$ Laboratory of Tissue Homeostasis and Disease, Skeletal Biology and Engineering Research Center, Department of Development and Regeneration, KU Leuven

${ }^{2}$ Division of Rheumatology, University Hospiłals teuven $^{\text {euven }}$

Corresponding Author: Prof. Rik Lories, Division of Rheumatology, UZ Leuven, Herestraat 49, B3000 Leuven, Belgium. Phone: +32-16342541; Fax:+32-16342543; Rik.Lories@uzleuven.be

MVM is the recipient of an Aspirant fellowship and GRG is the recipient of a post-doctoral fellowship from the Flanders Research Foundation (FWO-Vlaanderen). Research on the topic of the review is supported by FWO grants G094614 and G095916N.

Conflict of interest: Leuven Research and Development, the technology transfer office of $K U$ Leuven has received speaker's and consultancy fees on behalf of R.L. from Abbvie, BoehringerIngelheim, Celgene, Janssen, Novartis, Merck, Pfizer and UCB, and research grants from Boehringer-Ingelheim, Celgene and Pfizer. KDV reports speaker's and consultancy fees from Abbvie, Celgene, Johnson \& Johnson, Merck, Novartis, Pfizer and UCB. 


\section{Abstract}

Axial spondyloarthritis is a chronic inflammatory skeletal disorder with an important burden of disease, affecting the spine and sacroiliac joints and typically presenting in young adults. Ankylosing spondylitis, diagnosed by the presence of structural changes to the skeleton, is the prototype of this disease group. Bone disease in axial spondyloarthritis is a complex phenomenon with the coexistence of bone loss and new bone formation, both contributing to the morbidity of the disease, in addition to pain caused by inflammation. The skeletal structural changes respectively lead to increased fracture risk and to permanent disability caused by ankylosis of the sacroiliac joints and the spine. The mechanism of this new bone formation leading to ankylosis is insufficiently known. The process appears to originate from entheses, specialized structures that provide a transition zone in which tendon and ligaments insert into the underlying bone. Growth factor signaling pathways such as bone morphogenetic proteins, Wnts and Hedgehogs have been identified as molecular drivers of new bone formation, but the relationship between inflammation and activation of these pathways remains debated. Long-standing control of inflammation appears necessary to avoid ankylosis. Recent evidence and concepts suggest an important role for biomechanical factors in both onset and progression of the disease. With regards to new bone formation, these processes can be understood as ectopic repair responses secondary to inflammation-induced bone loss and instability. In this review, we discuss the clinical implications of the skeletal changes as well as the underlying molecular mechanisms, the relation between inflammation and new bone formation, and the potential role of biomechanical stress.

\section{Keywords}

axial spondyloarthritis, ankylosing spondylitis, enthesitis, enthesophytes, syndesmophytes 


\section{Introduction}

Axial spondyloarthritis (AxSpA) is a chronic inflammatory skeletal disease characterized by inflammation and by bony ankylosis of the spine and sacroiliac joints, leading to pain, stiffness and increasing disability. Axial spondyloarthritis as defined according to the ASAS (Assessment of SpondyloArthritis International Society) classification criteria [1] includes both radiographic and non-radiographic $\mathrm{AxSpA}$, depending on whether or not structural damage can be detected on conventional radiography. Radiographic AxSpA comprises ankylosing spondylitis (AS), the prototype of the disease as defined in the older modified New York criteria [2]. The inclusion of non-radiographic $\mathrm{AxSpA}$ in the new criteria raised the opportunity of earlier diagnosis and treatment. AxSpA belongs to the larger group of spondyloarthritides (SpA), which further include psoriatic arthritis (PsA), inflammatory bowel disease (IBD)-related arthritis, reactive arthritis (ReA), juvenile onset SpA and undifferentiated SpA. The enthesis, the anatomical zone where tendons and ligaments insert into the bone, is proposed to be the primary disease location in all SpA subtypes $[3,4]$. The enthesis is a transition tissue in which tendon or ligament fibers pass through uncalcified fibrocartilage, calcified fibrocartilage and then bone, thus providing a multilayered structure that can withstand biomechanical stress. Besides enthesitis, also other important disease characteristics are shared, meaning that the overlap between the different subsets is possible and common. This is the case for both musculoskeletal features like axial inflammation and peripheral arthritis, and extra-articular features like anterior uveitis, cutaneous psoriasis and gut inflammation, each of them more, but not exclusively, associated with AxSpA, PsA and IBD-related arthritis respectively $[5,6]$. New classification criteria distinguish patients with $\mathrm{SpA}$ according to the presence of predominantly axial or predominantly peripheral disease, a distinction used as the main guidance for therapeutic decisions [1,6].

AxSpA typically affects young individuals, often starting in late adolescence. AS is more common in males than in females but the gender distribution is more equal in the nonradiographic forms of AxSpA. The whole SpA concept has a strong multifactorial genetic component, and AxSpA is strongly associated with the presence of the HLA-B27 gene $[5,6]$.

Bone disease in $\mathrm{AxSpA}$, and by extension in other forms of $\mathrm{SpA}$, is a complex phenomenon with the presence of both bone loss and new bone formation having an impact on the clinical features of the disease [7]. Bone loss can appear as systemic bone loss, leading to an increased 
fracture risk, and as local bone erosions, the latter being most pronounced in other forms of SpA such as psoriatic arthritis, but also present in the sacroiliac joints and vertebrae in prototypic AxSpA. At the same time, new bone formation can lead to bridging or ankylosis between adjacent vertebrae or other bones, thus contributing to the structural progression of the disease. While the pathogenesis of bone loss can be partly understood from the knowledge gained in understanding rheumatoid arthritis [8], the mechanism of new bone formation which is so characteristic of AS remains an intriguing but not fully understood feature of the disease [9]. The established and emerging therapies can often dramatically improve the signs and symptoms of the active disease, but the effect of such interventions on structural disease progression may be less striking then initially hoped or anticipated. Furthermore, the structural progression of the disease is slow and variable, which makes it difficult to study.

In this review, we discuss the typical changes observed in the skeleton of AxSpA patients, their clinical implications, and the underlying disease mechanisms including molecular pathways, the complex relationship between inflammation and new bone formation and the potential role of biomechanical stress in this disease.

\section{Disease location in AxSpA}

Local bone disease: erosions and new bone formation

The most prominent sites of bone disease in AxSpA are the sacroiliac joints and the spine. The sacroiliac joint has a complicated S-shaped anatomy and consists of a superior ligamentous part and a lower synovial part. The complex anatomy of this joint and in particular its multiplane structure are a challenge for reproducible assessment on conventional radiographs. On magnetic resonance imaging (MRI), inflammation mostly presents as osteitis although sometimes synovitis can be seen. There is a preferential involvement of the ilium compared to the sacrum, which has a thicker layer of articular cartilage [10]. The first abnormality observed on a conventional radiograph is the blurring of the subchondral bone of the lower part of the iliac bone, often only visible after years of symptoms. Afterwards, erosions emerge with apparent widening of the joint space, followed by new bone formation with progressive sclerosis and ultimately total ankylosis of the joints [11] (Figure 1). The disease progression is variable among patients and may stop at any stage. 
109 In the spine, a similar sequence of events can be observed. MRI images mainly show osteitis. On conventional radiography, after local erosion of the vertebral corners, the so-called "squaring" of the vertebrae occurs, with subsequent reactive sclerosis resulting in "shiny corners", and development of erosions of the vertebral endplate (Figure 2). Ultimately, new bony protrusions are formed, originating from the entheses or attachment sites of ligaments into the vertebrae, in some cases leading to total ankylosis of the spine or a "bamboo spine" [11] (Figure 3). In peripheral joints, if affected, similar new bone formation can occur at the entheses. These bony protrusions formed at the entheses in the spine and peripheral joints are called syndesmophytes and enthesophytes respectively. They are characteristic but not unique for radiographic $\mathrm{AxSpA}$, since similar syndesmophyte formation can be seen in for example diffuse idiopathic skeletal hyperostosis (DISH), an age-related condition with extensiv new bone formation, but without preceding inflammation and with more limited functional impact [12].

The abnormalities seen on a conventional radiograph can take several years to develop. Earlier detection of sacroiliitis or spondylitis is possible with MRI with the presence of bone marrow edema or osteitis as a measure of inflammation (Figure 4). Furthermore, MRI can also detect fatty tissue-like deposition, a post-inflammatory lesion that has been suggested to be an intermediate stage between inflammation and new bone formation [13] and a possible prognostic factor for structural disease progression [14].

\section{Systemic bone loss}

Besides the coexistence of erosions and new bone formation at the outer bone margins at different axial levels, systemic bone loss of the vertebral bodies leading to possible fractures at any time in the disease process can be detected starting from an early disease stage [15], emphasizing the duality of bone disease in AxSpA .

\section{Clinical implications of bone disease}

\section{$\underline{\text { Local bone disease and structural disease progression }}$}

The clinical and functional outcome for patients with AxSpA depends not only on inflammation but also on structural progression of the disease, with inflammation being the major contributing factor in early disease, and structural changes becoming more important at later disease stages. Spinal inflammation as well as irreversible spinal damage independently 
139 influence spinal mobility and overall functioning $[16,17]$, and the correlation between the extent of spinal damage and worsening of the functional outcome increases in the presence of lower disease activity [17]. On the other hand, while tumor necrosis factor (TNF) inhibitors are an established therapy in AxSpA and thus lower the disease activity [5], Poddubnyy et al recently published that in AS patients successfully receiving this therapy, the overall functioning (measured as the Bath AS Functional Index or BASFI) remains almost stable despite the ongoing structural progression. Furthermore, changes in functioning correlated with fluctuations in disease activity and not with changes in structural progression [18]. Importantly, while the BASFI score seemed to be independent of structural progression in this study, there was some dependence for spinal mobility (measured with the Bath AS Metrology Index or BASMI), which is a more objective outcome measure for structural damage.

\section{Systemic bone loss leading to osteoporosis}

Besides new bone formation, also systemic bone loss contributes to the burden of disease. Osteoporosis in SpA has a multifactorial origin and can occur due to an increase of proinflammatory cytokines levels, physical inactivity secondary to pain or limited spinal mobility, malabsorption if inflammatory bowel disease is present or treatment with glucocorticoids. A recent cross-sectional observational study by Hauser et al investigated the presence of antibodies against osteoprotegerin (OPG) in 134 patients with AxSpA. OPG is a decoy receptor for RANKL, an important inducer of osteoclastogenesis, and antibodies against OPG have been identified in patients with rheumatoid arthritis where they were associated with increased bone resorption. Analogous to the findings in rheumatoid arthritis, these antibodies were present in $8.2 \%$ of the AxSpA patients in comparison with previous reported levels of $1-1.4 \%$ in healthy controls, and they were associated with lower hip bone-mineral density (BMD) and a history of fractures. This suggests a potential role of OPG in systemic bone loss in some of the patients [19].

The evidence of clinical impact of osteoporosis in AxSpA is abundant and vertebral fractures in an ankylosed spine carry a high risk of neurological complications [20]. A recent metaanalysis of studies examining the risk of vertebral and non-vertebral fractures in patients with AS confirmed a higher risk for vertebral and non-vertebral fractures, but not for hip fractures. Male sex, disease duration, extent of structural damage on imaging and low bone mineral density at hip and femoral neck (and not at the spine) were identified as major risk factors 
associated with vertebral fractures [15]. Timely screening performed with dual-energy x-ray absorptiometry (DXA) is essential but difficult as BMD measurement of the spine in an anterior-posterior view can be inaccurate due to concurrent ankylosis [7]. In patients with syndesmophytes, DXA of the hip or lateral spine can be performed. If available quantitative computed tomography is a valid tool to use as an accurate alternative to DXA, when performing DXA is not possible [21]. Moreover, fracture risk can be calculated, for example with the available online software Fracture Risk Assessment (FRAX) tool, which takes into account clinical risk factors with or without femoral neck BMD [22]. However, this technique has many limitations including the lack of validation of this score in patients with $\mathrm{AxSpA}$ and the restriction of use in patients over 40 years old. In addition, the combination of spinal ankylosis and trabecular bone loss secondary to inflammation puts the patients at risk for lowimpact trauma fractures (Figure 5 and Figure 6). Thus, a systematic and in-depth clinical and imaging approach after low-impact trauma in such patients is warranted to avoid late-stage neurological lesions due to instability of the spine.

\section{Molecular mechanisms involved in the ankylosis process}

New bone formation in the disease process of AxSpA should be distinguished from the new bone formation taking place during skeletal development and growth. Physiological new bone formation occurs through two different mechanisms: endochondral bone formation and membranous or direct bone formation [23]. In endochondral bone formation, progenitor cells first condensate and differentiate towards cartilage cells. Chondrocytes progressively become hypertrophic and subsequently transdifferentiate towards osteoblasts [24] or are replaced by osteoblast differentiated from osteoprogenitor cells [23]. In direct bone formation, no cartilage template is involved and progenitor cells directly become osteoblasts. After bone formation, homeostasis is maintained by a continuously renewal of bone by coordination or "coupling" of osteoblast and osteoclast function; a process called bone remodeling [25].

In AxSpA, aspects of both endochondral and membranous bone formation are present in the pathological new bone formation, with also evidence of cartilage metaplasia, where chondroid-like cells reside in a calcified bone-like matrix. Bone changes in AxSpA are clearly pathological: besides the exaggerated new bone formation at the outer margins of the bone through the three mechanisms listed above, extensive trabecular bone loss leading to osteoporosis and fractures takes place within the bones $[25,26]$. 
201 Not surprisingly, current evidence suggests that the key molecular signaling cascades involved 202 in the new bone formation process, are similar to those steering bone modeling and 203 remodeling. The bone morphogenetic protein (BMP), Wnt and Hedghog signaling pathways 204 normally required for normal skeletal development, growth and homeostasis, also appear to 205 be activated in the pathological new bone formation characteristic for AxSpA. This concept is supported by numerous in vitro, ex vivo and animal model data [27].

\section{Bone morphogenetic proteins}

The involvement of BMPs in joint ankylosis was initially identified in the ankylosing arthritis/enthesitis model of aging male DBA/1 mice [28]. Upon grouped caging, these male mice develop spontaneous peripheral arthritis of the hindpaws, in particular the toes, with extensive bone remodeling starting from the enthesis [29]. However, there is no current evidence of axial disease in this mouse model. Different BMPs are present in distinct stages of the disease and BMP-inhibitor noggin is able to stop the ankylosis process both in a preventive and therapeutic setting, confirming the key role for BMP in the pathogenesis [28]. BMPs mediate their effects through different signaling cascades in the cell. With regards to cartilage and bone differentiation, the main effects appear to be mediated by the SMAD phosphorylation cascade. Alternative pathways include activation of mitogen activated kinase p38. Although specific inhibition of p38 in vitro negatively affects chondrogenic differentiation, in vivo use of such an inhibitor in the DBA/1 model showed a paradoxal effect, possibly due to the short half-life of the compound used and associated rebound effects [30].

Direct evidence for involvement of BMP in humans with AxSpA remains limited. BMP signaling is activated in the entheses of patients with SpA [28] and two single nucleotide polymorphisms in BMP6 were found to be associated with radiographic severity in AS [31]. Recently, bone marrow derived mesenchymal stem cells (MSC) from AS patients were shown to have a greater osteogenic differentiation capacity compared to healthy donors, an effect that was attributed to an imbalance between BMP2 and the antagonist noggin. AS-MSCs secreted more BMP2 and less Noggin, which resulted in an increased SMAD and ERK1/2 MAPK signaling [32]. Of note, auto-antibodies against Noggin have been found in patients with AS [33], suggesting that these could contribute to excessive bone formation by blocking the BMP antagonist. 
Another important pathway may be Wnt signaling. This cascade is dependent on a group of 15 secreted Wnt glycoproteins that activate different signaling cascades, of which the betacatenin dependent canonical pathway is best studied [34]. The Wnt signaling pathway is essential for embryonic skeletal development and in growth and, as BMPs, plays a role in bone homeostasis later in life. The most prominent evidence that Wnts also have a role in pathological new bone formation comes from studies in a murine TNF overexpression model [35]. In this model reminiscent of rheumatoid arthritis, characterized by extensive inflammation and associated bone erosion and destruction, blocking antibodies against Dickkopf-1 (DKK1), a broad inhibitor of the beta-catenin dependent Wnt signaling cascade, shift the presentation of the model from destructive arthritis towards the formation of osteophytes and progressive ankylosis [35]. Interestingly, such features are not limited to limb joints but are also recognized in the sacroilliac joints [36]. These data suggest that Wnts may stimulate pathological bone formation and the development of ankylosis. Associated human ex vivo biomarkers studies further suggested that low levels of Wnt antagonists such as DKK1 and sclerostin are associated with more severe radiographic progression [37].

\section{$246 \quad$ Hedgehog}

247 Inhibition of Hedgehog signaling, which has a key role in the differentiation of hypertrophic chondrocytes during endochondral bone formation, leads to less osteophytes in a transient antibody-driven serum transfer model of arthritis [38]. This effect is in line with its known effects in skeletal development and growth. In their paper, Ruiz-Heiland and coworkers use a small molecule antagonist of hedgehog signaling, arguing that the specific role of hedgehogs in the transition from proliferating towards hypertrophic chondrocytes offers advantages when considering targeting this pathway as compared to BMPs and Wnts. Effectively, specific targeting of this step in endochondral bone formation may avoid side effects at the level of systemic bone remodeling that are hypothesized to be negative factors when considering clinical use of BMP and Wnt inhibition [38].

While these pathways are most likely the effector signals for the pathological new bone formation, the effective triggers for their activation remain unclear. However, the experience with new therapies in clinical practice shows that cytokines may not only lead to inflammation but also directly or indirectly induce bone changes, whether or not mediated via these pathways. In addition, the location of the lesions, and in particular the central role of the 

275

enthesis in SpA disease processes, puts into evidence that biomechanical factors may strongly contribute to AxSpA disease processes.

\section{The relationship between inflammation and new bone formation}

The introduction of targeted therapies blocking TNF or interleukin-17 (IL17) in the treatment of AxSpA patients has dramatically changed clinical practice [5]. Both strategies are highly effective in controlling signs and symptoms of the disease and thus have an important impact on the patients. Furthermore, control of inflammation by anti-TNF appears to have a strong impact on the bone loss leading to osteoporosis in AxSpA [39]. Taking into account the direct effects of IL17 on osteoclast differentiation [40], similar results are expected for anti-IL17 treatment. Despite these favorable findings, their effects on structural disease progression characterized by ankylosis remain unclear.

$273 \underline{T N F}$

274 As demonstrated by the effect of TNF-inhibition on inflammation and symptoms of the disease, TNF plays a key role in the pathogenesis of AxSpA. Bone resorption through stimulating osteoclastogenesis is a well-established effect [41], but the role of this cytokine and the effects of monoclonal antibodies or soluble receptors as therapeutics for structural disease progression in AxSpA are still debated.

Indeed, there is a long-standing discussion about the link between inflammation and new bone formation. Animal models showed that the overexpression of either human or murine TNF triggers erosive arthritis but does not lead to new bone formation [42,35]. Likewise, the inhibition of TNF in the aging DBA/1 spontaneous arthritis model of ankylosing enthesitis could not prevent it [43].

There is little evidence that inflammation would directly trigger new bone formation. We earlier suggested that inflammation and new bone formation are linked, but they are also molecularly largely independent processes, thereby suggesting the existence of a common trigger or an indirect relationship [44]. Other authors proposed the TNF-brake hypothesis, suggesting that TNF inhibits new bone formation by stimulating the expression of Wnt inhibitor DKK-1 [45]. This would entail that increased new bone formation and progression of ankylosis could be expected after successful treatment of inflammation, which was not confirmed in human studies [46]. 
292 Original cohort studies with a follow--up of two years from the initial anti-TNF clinical trials suggested that anti-TNF treatments did not affect structural disease progression within this time frame [47-49]. However, as first suggested by the results of Haroon et al [50], an increasing number of long-term follow-up studies do show a reduction in new bone formation if treatment starts early in the course of the disease or if it is continued for more than 4 years. Maas et al [51] have shown a deflection in the linear course of structural progression in the spine after 6 and 8 years of TNF-inhibition. It is important to notice that these long-term studies contain data from both the monoclonal antibodies and the soluble receptor etanercept. However, in the case of inflammatory bowel disease, the therapy with etanercept has shown to be ineffective or even detrimental in contrast with the other TNF-inhibitors suggesting an, at this moment, insufficiently known different pathophysiological effect [52]. For this reason, new studies analyzing data only concerning etanercept would be of interest. Taken together these data may suggest that active inflammation provides a direct or indirect trigger for new bone formation and that sustained inhibition of inflammation or the prevention of development of disease in new sites is necessary to avoid long-term structural disease progression and consequences. As discussed below and before [53], loss of bone and biomechanical instability may be such a trigger.

Another molecular and cellular explanation can be found in paradoxical effects of TNF on osteoblasts. In vitro studies on human mesenchymal stem cells have shown that TNF can behave as an inhibitor or stimulator of osteoblastogenesis through modeling of the BMP and Wnt pathways, depending on concentration and cell type [41]. In an environment where osteoclasts are less present, as in the enthesis, the stimulating effect on osteoblasts could become more obvious.

315 These recent results point out that TNF-inhibition can prevent structural progression if given 316 early and for long duration, most likely by taking away triggers for new bone formation and 317 by preventing the development of new disease sites.

\section{$318 \quad$ IL17}

319 Initial interest in the IL17 axis in AxSpA emerged almost a decade ago with promising data 320 from genetic studies and animal models [54]. Since then, successful clinical trials have been 
321 performed [55] and secukinumab, a monoclonal antibody directed against IL-17A, is used in 322 clinical practice for the treatment of AxSpA patients.

323 IL17 can lead to bone loss through two different mechanisms depending on the cellular and 324 tissue context. In the case of local inflammatory bone disease such as in rheumatoid arthritis, 325 it is produced by cells in the synovium and induces RANKL production, a strong stimulator of 326 osteoclastogenesis [56]. In the case of a distant source of production, such as in the 327 inflammatory skin disease psoriasis, IL17 exerts its effects on the bone through inhibition of osteoblast activity by inhibiting the Wnt pathway $[57,58]$. In AxSpA, both mechanisms could play a role.

However, as described above for TNF [41], effects on the bone are heterogeneous and sometimes difficult to comprehend [59]: In mesenchymal stem cells or fibroblast like synoviocytes, IL17A, together with TNF, induces new bone formation by reducing the levels of RANKL and DKK-1 $[60,61]$. This in contrast with the increased expression of DKK-1 that has been observed in fibroblast like synoviocytes of patients with rheumatoid arthritis compared with those from patients with osteoarthritis [35]. The authors put forward the Schnurri-3 gene as a gene of interest. Schnurri-3 is known as a regulator of skeletal remodeling in mice [62], and is upregulated by IL17 in combination with TNF in isolated fibroblast like cells [61]. While in whole bone, upregulation of Schnurri-3 acts as an inhibitor of osteogenesis, in the absence of osteoclasts, as is the case in the in vitro experiments, but as can also be expected in, for example, the enthesis, and then leads to increased osteogenesis.

Recently, two-years data for secukinumab treatment and new bone formation became available. The study shows a low rate of radiographic progression, but long-term follow-up is necessary before drawing conclusions [63]. Interestingly, data in the spontaneous model of ankylosing enthesitis in DBA/1 mice suggest that inhibition of IL17 is effective in preventing joint ankylosis [64]. Effectively, some in vivo data also suggest that IL17 may stimulate new bone formation [65]. Further data from the clinical cohorts should provide further insights into the question whether the effects of IL17 with regards to structural disease progression are different from those of targeting TNF. Caution should be applied when data from different studies are compared as the availability of anti-TNF over the last decade may have had an impact on the characteristics of patient populations included in current clinical trials. 
Despite the availability of biologicals, NSAIDs remain the first line therapy in AxSpA [66]. A possible inhibitory effect of NSAIDs on structural progression was already reported in a retrospective study in 1976 for phenylbutazone [67], and later confirmed in a randomized clinical trial in AS patients starting with celecoxib. Nevertheless, the recent ENRADAS study with diclofenac could not confirm these data [66]. The overall expectation at the start of the COX2-inhibition leading to decreased PGE2, which stimulates osteoclast and osteoblast activity. However, celecoxib was shown to have different effects on reparative bone formation compared to non-selective NSAIDs [66], and COX-inhibition may only be one of the modes of action of NSAIDs: the importance of COX-independent effects could therefore be underestimated. At present, there is an ongoing trial comparing the effect of treatment with NSAIDs added to anti-TNF therapy (Celecoxib + Golimumab) versus anti-TNF therapy alone (Golimumab) (CONSUL trial) [68].

\section{Biomechanical stress as a driver of inflammation}

There are a number of arguments pointing towards an important role for mechanical loading and stress in the pathogenesis of AxSpA. Not only SpA mainly affects the axial skeleton, which is exposed to significant load and biomechanical stress, but also it involves preferentially the lower limbs compared to the upper limbs, suggesting that their role as recipients of the translational forces coming from the spine through the sacroiliac joints makes them exposed to higher mechanical loading [53]. The musculoskeletal system is designed to provide structure and stability to the body while simultaneously allowing movement. The first signs of disease in SpA can often be found at the entheses, a site of important biomechanical stress as the insertion of tendons and ligaments into the bone serves to transmit and spread mechanical forces [3]. It appears likely that such mechanical forces can also induce microdamage that may trigger local inflammation. Indeed, the identification of resident inflammatory cells in the enthesis [69] strengthens this view: they might be able to react to danger signals or neo-epitopes appearing as a consequence of micro-damage in the environment or to changes in their cytoskeleton caused by forces and thus being indirectly mechanosensitive [53]. Current evidence suggests that these cells are able to trigger IL17 production and therefore inflammation [70]. 
Jacques et al [42] were the first to provide direct evidence in a murine model for the contribution of biomechanical loading to both onset of inflammation and new bone formation. They first demonstrated that in TNF $\triangle A R E$ mice, a TNF overexpression model leading to development of arthritis and spondylitis, inflammation of the joints starts at the enthesis and is T-cell independent. Onset of inflammation could be prevented through unloading of the hind paws by tail suspension [42]. Furthermore, the mechanical forces exert their effect on that location through the ERK1/2 MAPK pathway. Since new bone formation does not appear in the murine TNF overexpression models, they used a similar approach in the collagen-antibody-induced arthritis model (CAIA) in DBA/1 mice where they showed that unloading could also prevent new bone formation. Thus, biomechanical stress may trigger inflammation and therefore provide an indirect trigger for subsequent new bone formation.

As a consequence, the main trigger for new bone formation may be a result of inflammation. The bone, and in particular the osteocytes, are known to be mechanosensitive. Osteocytes influence the activity of osteoblasts and osteoclasts, a principle well known in the field of osteoporosis since unloading triggers bone loss through this mechanism and vice versa [27]. Thus, in addition to damage induced by biomechanical stress, systemic bone loss may trigger bone formation.

Taken together these two effects of mechanical loading on the bone, biomechanical stress contributes to both the onset and the progression phase of the disease $[53,71]$. Initial biomechanical loading could trigger onset of inflammation, which leads to bone loss. In its turn, bone loss represents instability, another type of biomechanical stress, leading to more bone formation. As persistent inflammation in the vertebral bodies may prevent the anabolic response, we have put forward that alternative sites would be involved in an effort to correct the instability. This would result in the formation of syndesmophytes: compensatory stability for the spine but with a loss of normal mobility as the price to pay [71]. Why the initial biomechanical trigger first elicits inflammation and not immediately new bone formation remains to be investigated, but differences in the type of biomechanical triggers exerted on the bone provide a possible explanation.

\section{Conclusion}


AxSpA is characterized by inflammation and new bone formation both substantially contributing to the burden of disease. New bone formation can lead to spinal or sacroiliac joint ankylosis, reduced mobility and increased disability. In addition, even partial ankylosis may change the biomechanical properties of the spine and trigger additional mechanicallymediated pain. Inflammation is known to play a crucial role in the onset and further development of AxSpA, but whether this disease progression happens solely because of the sustained production of pro-inflammatory cytokines or because of an attempt of the body to compensate the bone loss needs to be further investigated. Moreover, the correlation between the decreased BMD and the new bone formation still needs to be clarified. Effective anti-inflammatory strategies are likely to have a positive long-term effect on structural damage including ankylosis. In particular, they might be effective in preventing the development of new disease sites and they do contribute to reversal of the systemic bone loss that represents a possible trigger for syndesmophyte-linked ankylosis.

\section{$424 \quad$ Figure legends}

425 Figure 1: Pelvic radiographs demonstrating different stages of structural disease progression 426 in radiographic axial spondyloarthritis. a Erosive changes (depicted by an arrow) with 427 subchondral sclerosis (dashed arrows). b Progressive sclerosis (dashed arrows) in the same patient seven years later. c Total ankylosis (asterisks) of both sacroiliac joints in a patient with longstanding disease.

Figure 2: Radiograph of the lumbar spine of a patient with radiographic axial spondyloarthritis demonstrating squaring (depicted by asterisks) and shiny corners (arrows) of thoracic and lumbar vertebrae.

Figure 3: Consecutive radiographs of the lumbar spine in a non-treated patient with axial spondyloarthritis. a Normal vertebrae. b Bridging syndesmophytes (depicted by arrows) forming a bamboo spine, 7 years later.

Figure 4: Magnetic Resonance Imaging (MRI) showing early features of axial spondyloarthritis. a Bone marrow edema in the caudal part of the left sacroiliac joint (depicted by arrow). $\mathbf{b}$ Bone marrow edema appearing as 'shiny corners' in some thoracic vertebrae (dashed arrows).

Figure 5: Cervical fracture after minor trauma in a patient with longstanding axial spondyloarthritis with a bamboo spine. a Before trauma; conventional radiograph showing 
total cervical ankylosis, osteosynthetic material present from cervical vertebrae $\mathrm{C} 6$ to thoracic vertebra T1 after former traffic accident. b After trauma; computed tomography of the cervical spine performed at the emergency department because of cervical pain without neurological symptoms after minor trauma, showing a cervical fracture (depicted by arrow).

445 Figure 6: Fracture of the spine in a patient with longstanding axial spondyloarthritis. a 446 Radiograph before trauma showing a bamboo spine. b Computed tomography of the spine 447 performed because of lumbar pain without neurological symptoms after a fall, demonstrating 448 a complex fracture of thoracic vertebrae T11. c Radiograph after spinal fusion surgery of 449 vertebrae T9-L1.

450 Figure 7: Diagram of the disease mechanisms described in this article, emphasizing the 451 complex relationship between inflammatory cytokines, molecular pathways and the bone. 452 Biomechanical stress is hypothesized to be an initial trigger for inflammation by eliciting 453 microdamage, but it might also contribute to new bone formation later in the disease, as a 454 result of the instability due to bone loss. The connections indicated with * are traditionally 455 viewed in the depicted way, but they may also exert an opposite effect depending on source 456 of production and the location of target, as discussed in the text. (IL17 interleukin-17, TNF 457 tumor necrosis factor, OPG osteoprotegerin, RANKL receptor activator of nuclear factor 458 kappa-beta ligand, DKK1 dickkopf-related protein 1, BMP bone morphogenetic protein, Hh 459 hedgehog). 
463 464 465 466 467 468 469 470 470 471 472 473 474 474 475 476 477 478 479 480 481 482 483 484 485 486 487 488 489 490 491 492 493 39494 495

1. Rudwaleit M, van der Heijde D, Landewe R, Listing J, Akkoc N, Brandt J, Braun J, Chou CT, Collantes-Estevez E, Dougados M, Huang F, Gu J, Khan MA, Kirazli Y, Maksymowych WP, Mielants H, Sorensen IJ, Ozgocmen S, Roussou E, Valle-Onate R, Weber U, Wei J, Sieper J (2009) The development of Assessment of SpondyloArthritis international Society classification criteria for axial spondyloarthritis (part II): validation and final selection. Ann Rheum Dis 68 (6):777-783. doi:10.1136/ard.2009.108233

2. van der Linden S, Valkenburg HA, Cats A (1984) Evaluation of diagnostic criteria for ankylosing spondylitis. A proposal for modification of the New York criteria. Arthritis Rheum 27 (4):361-368 3. McGonagle D, Lories RJ, Tan AL, Benjamin M (2007) The concept of a "synovio-entheseal complex" and its implications for understanding joint inflammation and damage in psoriatic arthritis and beyond. Arthritis Rheum 56 (8):2482-2491. doi:10.1002/art.22758

4. McGonagle D, Gibbon W, Emery P (1998) Classification of inflammatory arthritis by enthesitis. Lancet 352 (9134):1137-1140. doi:10.1016/S0140-6736(97)12004-9

5. Sieper J, Poddubnyy D (2017) Axial spondyloarthritis. Lancet. doi:10.1016/S0140-6736(16)31591-4 6. Rudwaleit M, van der Heijde D, Landewe R, Akkoc N, Brandt J, Chou CT, Dougados M, Huang F, Gu J, Kirazli Y, Van den Bosch F, Olivieri I, Roussou E, Scarpato S, Sorensen IJ, Valle-Onate R, Weber U, Wei J, Sieper J (2011) The Assessment of SpondyloArthritis International Society classification criteria for peripheral spondyloarthritis and for spondyloarthritis in general. Ann Rheum Dis 70 (1):25-31. doi:10.1136/ard.2010.133645

7. Carter S, Lories RJ (2011) Osteoporosis: a paradox in ankylosing spondylitis. Curr Osteoporos Rep 9 (3):112-115. doi:10.1007/s11914-011-0058-z

8. Schett G, Gravallese E (2012) Bone erosion in rheumatoid arthritis: mechanisms, diagnosis and treatment. Nat Rev Rheumatol 8 (11):656-664. doi:10.1038/nrrheum.2012.153

9. Shaw AT, Gravallese EM (2016) Mediators of inflammation and bone remodeling in rheumatic disease. Semin Cell Dev Biol 49:2-10. doi:10.1016/j.semcdb.2015.10.013

10. Navallas M, Ares J, Beltran B, Lisbona MP, Maymo J, Solano A (2013) Sacroiliitis associated with axial spondyloarthropathy: new concepts and latest trends. Radiographics 33 (4):933-956. doi:10.1148/rg.334125025

11. Maksymowych WP (2016) Imaging in Axial Spondyloarthritis: Evaluation of Inflammatory and Structural Changes. Rheum Dis Clin North Am 42 (4):645-662. doi:10.1016/j.rdc.2016.07.003 12. Berthelot JM, Le Goff B, Maugars Y (2013) Pathogenesis of hyperostosis: a key role for mesenchymatous cells? Joint Bone Spine 80 (6):592-596. doi:10.1016/j.jbspin.2013.03.013 13. Machado PM, Baraliakos X, van der Heijde D, Braun J, Landewe R (2016) MRI vertebral corner inflammation followed by fat deposition is the strongest contributor to the development of new bone at the same vertebral corner: a multilevel longitudinal analysis in patients with ankylosing spondylitis. Ann Rheum Dis 75 (8):1486-1493. doi:10.1136/annrheumdis-2015-208011 14. Maksymowych WP, Wichuk S, Chiowchanwisawakit P, Lambert RG, Pedersen SJ (2017) Fat metaplasia on MRI of the sacroiliac joints increases the propensity for disease progression in the spine of patients with spondyloarthritis. RMD Open 3 (1):e000399. doi:10.1136/rmdopen-2016000399

15. Pray C, Feroz NI, Nigil Haroon N (2017) Bone Mineral Density and Fracture Risk in Ankylosing Spondylitis: A Meta-Analysis. Calcif Tissue Int. doi:10.1007/s00223-017-0274-3

16. Machado P, Landewe R, Braun J, Hermann KG, Baker D, van der Heijde D (2010) Both structural damage and inflammation of the spine contribute to impairment of spinal mobility in patients with ankylosing spondylitis. Ann Rheum Dis 69 (8):1465-1470. doi:10.1136/ard.2009.124206

17. Landewe R, Dougados M, Mielants $H$, van der Tempel $H$, van der Heijde D (2009) Physical function in ankylosing spondylitis is independently determined by both disease activity and radiographic damage of the spine. Ann Rheum Dis 68 (6):863-867. doi:10.1136/ard.2008.091793 
18. Poddubnyy D, Fedorova A, Listing J, Haibel H, Baraliakos X, Braun J, Sieper J (2016) Physical

Function and Spinal Mobility Remain Stable Despite Radiographic Spinal Progression in Patients with Ankylosing Spondylitis Treated with TNF-alpha Inhibitors for Up to 10 Years. J Rheumatol 43 (12):2142-2148. doi:10.3899/jrheum.160594

19. Hauser B, Zhao S, Visconti MR, Riches PL, Fraser WD, Piec I, Goodson NJ, Ralston SH (2017) Autoantibodies to Osteoprotegerin are Associated with Low Hip Bone Mineral Density and History of Fractures in Axial Spondyloarthritis: A Cross-Sectional Observational Study. Calcif Tissue Int. doi:10.1007/s00223-017-0291-2

20. Leone A, Marino M, Dell'Atti C, Zecchi V, Magarelli N, Colosimo C (2016) Spinal fractures in patients with ankylosing spondylitis. Rheumatol Int 36 (10):1335-1346. doi:10.1007/s00296-0163524-1

21. Mandl P, Navarro-Compan V, Terslev L, Aegerter $P$, van der Heijde D, D'Agostino MA, Baraliakos X, Pedersen SJ, Jurik AG, Naredo E, Schueller-Weidekamm C, Weber U, Wick MC, Bakker PA, Filippucci E, Conaghan PG, Rudwaleit M, Schett G, Sieper J, Tarp S, Marzo-Ortega H, Ostergaard M, European League Against R (2015) EULAR recommendations for the use of imaging in the diagnosis and management of spondyloarthritis in clinical practice. Ann Rheum Dis 74 (7):1327-1339. doi:10.1136/annrheumdis-2014-206971 22. Kanis JA, McCloskey E, Johansson H, Oden A, Leslie WD (2012) FRAX((R)) with and without bone mineral density. Calcif Tissue Int 90 (1):1-13. doi:10.1007/s00223-011-9544-7 23. Lefebvre V, Bhattaram P (2010) Vertebrate skeletogenesis. Curr Top Dev Biol 90:291-317. doi:10.1016/S0070-2153(10)90008-2

24. Zhou X, von der Mark K, Henry S, Norton W, Adams H, de Crombrugghe B (2014) Chondrocytes transdifferentiate into osteoblasts in endochondral bone during development, postnatal growth and fracture healing in mice. PLoS Genet 10 (12):e1004820. doi:10.1371/journal.pgen.1004820 25. Lories RJ, Schett G (2012) Pathophysiology of new bone formation and ankylosis in spondyloarthritis. Rheum Dis Clin North Am 38 (3):555-567. doi:10.1016/j.rdc.2012.08.003 26. Lories $R$ (2011) The balance of tissue repair and remodeling in chronic arthritis. Nat Rev Rheumatol 7 (12):700-707. doi:10.1038/nrrheum.2011.156

27. Gonzalez-Chavez SA, Quinonez-Flores CM, Pacheco-Tena C (2016) Molecular mechanisms of bone formation in spondyloarthritis. Joint Bone Spine 83 (4):394-400. doi:10.1016/j.jbspin.2015.07.008 28. Lories RJ, Derese I, Luyten FP (2005) Modulation of bone morphogenetic protein signaling inhibits the onset and progression of ankylosing enthesitis. J Clin Invest 115 (6):1571-1579. doi:10.1172/JCI23738

29. Lories RJ, Matthys P, de Vlam K, Derese I, Luyten FP (2004) Ankylosing enthesitis, dactylitis, and onychoperiostitis in male DBA/1 mice: a model of psoriatic arthritis. Ann Rheum Dis 63 (5):595-598. doi:10.1136/ard.2003.013599

30. Braem K, Luyten FP, Lories RJ (2012) Blocking p38 signalling inhibits chondrogenesis in vitro but not ankylosis in a model of ankylosing spondylitis in vivo. Ann Rheum Dis 71 (5):722-728. doi:10.1136/annrheumdis-2011-200377

31. Joo YB, Bang SY, Kim TH, Shim SC, Lee S, Joo KB, Kim JH, Min HJ, Rahman P, Inman RD (2014) Bone morphogenetic protein 6 polymorphisms are associated with radiographic progression in ankylosing spondylitis. PLoS One 9 (8):e104966. doi:10.1371/journal.pone.0104966

32. Xie Z, Wang P, Li Y, Deng W, Zhang X, Su H, Li D, Wu Y, Shen H (2016) Imbalance Between Bone Morphogenetic Protein 2 and Noggin Induces Abnormal Osteogenic Differentiation of Mesenchymal Stem Cells in Ankylosing Spondylitis. Arthritis Rheumatol 68 (2):430-440. doi:10.1002/art.39433 33. Tsui FW, Tsui HW, Las Heras F, Pritzker KP, Inman RD (2014) Serum levels of novel noggin and sclerostin-immune complexes are elevated in ankylosing spondylitis. Ann Rheum Dis 73 (10):18731879. doi:10.1136/annrheumdis-2013-203630 34. Nusse R, Clevers H (2017) Wnt/beta-Catenin Signaling, Disease, and Emerging Therapeutic Modalities. Cell 169 (6):985-999. doi:10.1016/j.cell.2017.05.016 
35. Diarra D, Stolina M, Polzer K, Zwerina J, Ominsky MS, Dwyer D, Korb A, Smolen J, Hoffmann M, Scheinecker C, van der Heide D, Landewe R, Lacey D, Richards WG, Schett G (2007) Dickkopf-1 is a master regulator of joint remodeling. Nat Med 13 (2):156-163. doi:10.1038/nm1538

36. Uderhardt S, Diarra D, Katzenbeisser J, David JP, Zwerina J, Richards W, Kronke G, Schett G (2010) Blockade of Dickkopf (DKK)-1 induces fusion of sacroiliac joints. Ann Rheum Dis 69 (3):592-597. doi:10.1136/ard.2008.102046

37. Heiland GR, Appel H, Poddubnyy D, Zwerina J, Hueber A, Haibel H, Baraliakos X, Listing J, Rudwaleit M, Schett G, Sieper J (2012) High level of functional dickkopf-1 predicts protection from syndesmophyte formation in patients with ankylosing spondylitis. Annals of the Rheumatic Diseases 71 (4):572-574. doi:10.1136/annrheumdis-2011-200216

38. Ruiz-Heiland G, Horn A, Zerr P, Hofstetter W, Baum W, Stock M, Distler JH, Nimmerjahn F, Schett G, Zwerina J (2012) Blockade of the hedgehog pathway inhibits osteophyte formation in arthritis. Ann Rheum Dis 71 (3):400-407. doi:10.1136/ard.2010.148262

39. Haroon NN, Sriganthan J, Al Ghanim N, Inman RD, Cheung AM (2014) Effect of TNF-alpha inhibitor treatment on bone mineral density in patients with ankylosing spondylitis: a systematic review and meta-analysis. Semin Arthritis Rheum 44 (2):155-161. doi:10.1016/j.semarthrit.2014.05.008 40. Yago T, Nanke Y, Ichikawa N, Kobashigawa T, Mogi M, Kamatani N, Kotake S (2009) IL-17 induces osteoclastogenesis from human monocytes alone in the absence of osteoblasts, which is potently inhibited by anti-TNF-alpha antibody: a novel mechanism of osteoclastogenesis by IL-17. J Cell Biochem 108 (4):947-955. doi:10.1002/jcb.22326

41. Osta B, Benedetti G, Miossec P (2014) Classical and Paradoxical Effects of TNF-alpha on Bone Homeostasis. Front Immunol 5:48. doi:10.3389/fimmu.2014.00048

42. Jacques $P$, Lambrecht $S$, Verheugen $E$, Pauwels $E$, Kollias $G$, Armaka M, Verhoye M, Van der Linden A, Achten R, Lories RJ, Elewaut D (2014) Proof of concept: enthesitis and new bone formation in spondyloarthritis are driven by mechanical strain and stromal cells. Ann Rheum Dis 73 (2):437-445. doi:10.1136/annrheumdis-2013-203643

43. Lories RJ, Derese I, de Bari C, Luyten FP (2007) Evidence for uncoupling of inflammation and joint remodeling in a mouse model of spondylarthritis. Arthritis Rheum 56 (2):489-497. doi:10.1002/art.22372

44. Lories RJ, Luyten FP, de Vlam K (2009) Progress in spondylarthritis. Mechanisms of new bone formation in spondyloarthritis. Arthritis Res Ther 11 (2):221. doi:10.1186/ar2642 45. Maksymowych WP, Chiowchanwisawakit P, Clare T, Pedersen SJ, Ostergaard M, Lambert RG (2009) Inflammatory lesions of the spine on magnetic resonance imaging predict the development of new syndesmophytes in ankylosing spondylitis: evidence of a relationship between inflammation and new bone formation. Arthritis Rheum 60 (1):93-102. doi:10.1002/art.24132

46. Baraliakos X, Haibel H, Listing J, Sieper J, Braun J (2014) Continuous long-term anti-TNF therapy does not lead to an increase in the rate of new bone formation over 8 years in patients with ankylosing spondylitis. Ann Rheum Dis 73 (4):710-715. doi:10.1136/annrheumdis-2012-202698 47. van der Heijde D, Salonen D, Weissman BN, Landewe R, Maksymowych WP, Kupper H, Ballal S, Gibson E, Wong R, Canadian study g, group As (2009) Assessment of radiographic progression in the spines of patients with ankylosing spondylitis treated with adalimumab for up to 2 years. Arthritis Res Ther 11 (4):R127. doi:10.1186/ar2794

48. van der Heijde D, Landewe R, Baraliakos X, Houben $H$, van Tubergen A, Williamson $P, X u$ W, Baker D, Goldstein N, Braun J, Ankylosing Spondylitis Study for the Evaluation of Recombinant Infliximab Therapy Study G (2008) Radiographic findings following two years of infliximab therapy in patients with ankylosing spondylitis. Arthritis Rheum 58 (10):3063-3070. doi:10.1002/art.23901 49. van der Heijde D, Landewe R, Einstein S, Ory P, Vosse D, Ni L, Lin SL, Tsuji W, Davis JC, Jr. (2008) Radiographic progression of ankylosing spondylitis after up to two years of treatment with etanercept. Arthritis Rheum 58 (5):1324-1331. doi:10.1002/art.23471 50. Haroon N, Inman RD, Learch TJ, Weisman MH, Lee M, Rahbar MH, Ward MM, Reveille JD, Gensler LS (2013) The impact of tumor necrosis factor alpha inhibitors on radiographic progression in ankylosing spondylitis. Arthritis Rheum 65 (10):2645-2654. doi:10.1002/art.38070 
51. Maas F, Arends S, Brouwer E, Essers I, van der Veer E, Efde M, van Ooijen PM, Wolf R, Veeger NJ, Bootsma H, Wink FR, Spoorenberg A (2016) Reduction in spinal radiographic progression in ankylosing spondylitis patients receiving prolonged treatment with TNF-alpha inhibitors. Arthritis Care Res (Hoboken). doi:10.1002/acr.23097

52. Guillot X, Prati C, Sondag M, Wendling D (2017) Etanercept for treating axial spondyloarthritis. Expert Opin Biol Ther 17 (9):1173-1181. doi:10.1080/14712598.2017.1347156

53. Van Mechelen M, Lories RJ (2016) Microtrauma: no longer to be ignored in spondyloarthritis? Curr Opin Rheumatol 28 (2):176-180. doi:10.1097/BOR.0000000000000254

54. Cheung PP (2017) Anti-IL17A in Axial Spondyloarthritis-Where Are We At? Front Med (Lausanne) 4:1. doi:10.3389/fmed.2017.00001

55. Baeten D, Sieper J, Braun J, Baraliakos X, Dougados M, Emery P, Deodhar A, Porter B, Martin R, Andersson M, Mpofu S, Richards HB, Group MS, Group MS (2015) Secukinumab, an Interleukin-17A Inhibitor, in Ankylosing Spondylitis. N Engl J Med 373 (26):2534-2548. doi:10.1056/NEJMoa1505066 56. Croes M, Oner FC, van Neerven D, Sabir E, Kruyt MC, Blokhuis TJ, Dhert WJ, Alblas J (2016) Proinflammatory T cells and IL-17 stimulate osteoblast differentiation. Bone 84:262-270. doi:10.1016/j.bone.2016.01.010 57. Uluckan O, Jimenez M, Karbach S, Jeschke A, Grana O, Keller J, Busse B, Croxford AL, Finzel S, Koenders M, van den Berg W, Schinke T, Amling M, Waisman A, Schett G, Wagner EF (2016) Chronic skin inflammation leads to bone loss by IL-17-mediated inhibition of Wnt signaling in osteoblasts. Sci Transl Med 8 (330):330ra337. doi:10.1126/scitranslmed.aad8996

58. Uluckan O, Wagner EF (2016) Role of IL-17A signalling in psoriasis and associated bone loss. Clin Exp Rheumatol 34 (4 Suppl 98):17-20

59. Miossec $P$ (2017) Update on interleukin-17: a role in the pathogenesis of inflammatory arthritis and implication for clinical practice. RMD Open 3 (1):e000284. doi:10.1136/rmdopen-2016-000284 60. Osta B, Lavocat F, Eljaafari A, Miossec P (2014) Effects of Interleukin-17A on Osteogenic Differentiation of Isolated Human Mesenchymal Stem Cells. Front Immunol 5:425. doi:10.3389/fimmu.2014.00425

61. Lavocat F, Osta B, Miossec P (2016) Increased sensitivity of rheumatoid synoviocytes to Schnurri3 expression in TNF-alpha and IL-17A induced osteoblastic differentiation. Bone 87:89-96. doi:10.1016/j.bone.2016.04.008

62. Wein MN, Jones DC, Shim JH, Aliprantis AO, Sulyanto R, Lazarevic V, Poliachik SL, Gross TS, Glimcher LH (2012) Control of bone resorption in mice by Schnurri-3. Proc Natl Acad Sci U S A 109 (21):8173-8178. doi:10.1073/pnas.1205848109

63. Braun J, Baraliakos X, Deodhar A, Baeten D, Sieper J, Emery P, Readie A, Martin R, Mpofu S, Richards HB, group Ms (2016) Effect of secukinumab on clinical and radiographic outcomes in ankylosing spondylitis: 2-year results from the randomised phase III MEASURE 1 study. Ann Rheum Dis. doi:10.1136/annrheumdis-2016-209730

64. Ebihara S, Date F, Dong Y, Ono M (2015) Interleukin-17 is a critical target for the treatment of ankylosing enthesitis and psoriasis-like dermatitis in mice. Autoimmunity 48 (4):259-266.

doi:10.3109/08916934.2014.976630

65. Ono T, Okamoto K, Nakashima T, Nitta T, Hori S, Iwakura Y, Takayanagi H (2016) IL-17-producing gammadelta T cells enhance bone regeneration. Nat Commun 7:10928. doi:10.1038/ncomms10928 66. Sieper J, Listing J, Poddubnyy D, Song IH, Hermann KG, Callhoff J, Syrbe U, Braun J, Rudwaleit M (2016) Effect of continuous versus on-demand treatment of ankylosing spondylitis with diclofenac over 2 years on radiographic progression of the spine: results from a randomised multicentre trial (ENRADAS). Ann Rheum Dis 75 (8):1438-1443. doi:10.1136/annrheumdis-2015-207897 67. Boersma JW (1976) Retardation of ossification of the lumbar vertebral column in ankylosing spondylitis by means of phenylbutazone. Scand J Rheumatol 5 (1):60-64 68. Proft F, Muche B, Listing J, Rios-Rodriguez V, Sieper J, Poddubnyy D (2017) Study protocol: COmparison of the effect of treatment with Nonsteroidal anti-inflammatory drugs added to antitumour necrosis factor a therapy versus anti-tumour necrosis factor a therapy alone on progression of StrUctural damage in the spine over two years in patients with ankyLosing spondylitis (CONSUL) - 
an open-label randomized controlled multicenter trial. BMJ Open 7 (6):e014591. doi:10.1136/bmjopen-2016-014591 69. Sherlock JP, Joyce-Shaikh B, Turner SP, Chao CC, Sathe M, Grein J, Gorman DM, Bowman EP, McClanahan TK, Yearley JH, Eberl G, Buckley CD, Kastelein RA, Pierce RH, Laface DM, Cua DJ (2012) IL-23 induces spondyloarthropathy by acting on ROR-gammat+ CD3+CD4-CD8- entheseal resident T cells. Nat Med 18 (7):1069-1076. doi:10.1038/nm.2817 70. Cuthbert RJ, Fragkakis EM, Dunsmuir R, Li Z, Coles M, Marzo-Ortega H, Giannoudis P, Jones E, ElSherbiny YM, McGonagle D (2017) Human Enthesis Group 3 Innate Lymphoid Cells. Arthritis Rheumatol. doi:10.1002/art.40150 71. Neerinckx B, Lories R (2017) Mechanisms, impact and prevention of pathological bone regeneration in spondyloarthritis. Curr Opin Rheumatol. doi:10.1097/BOR.0000000000000404 


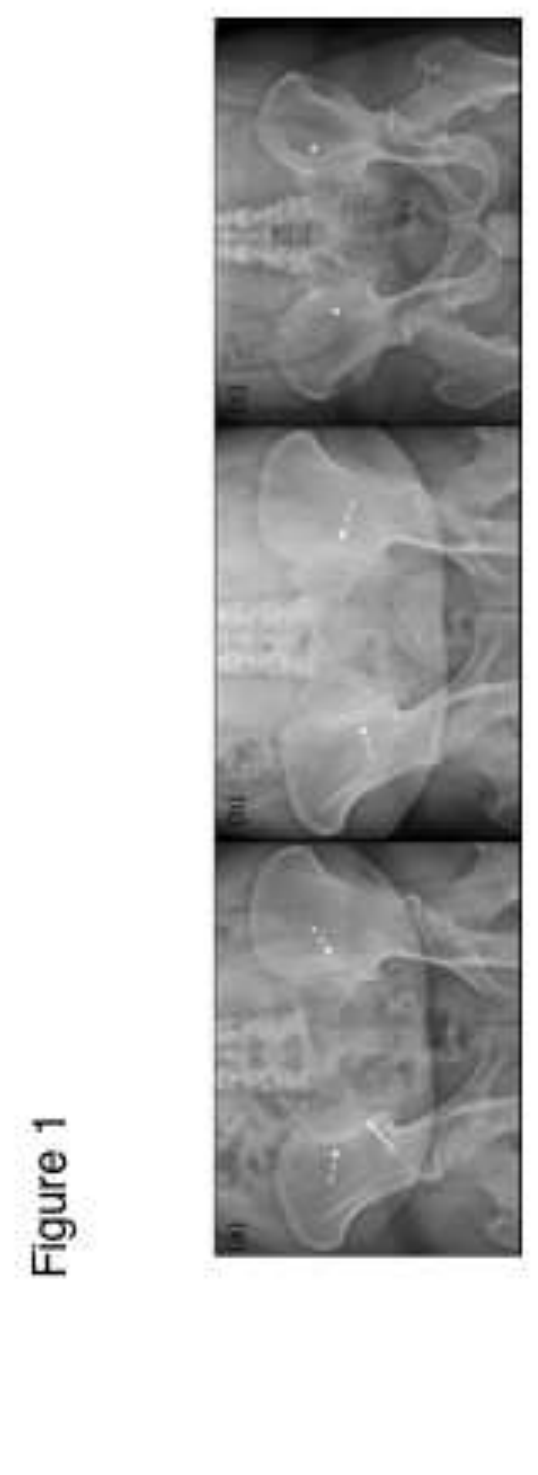




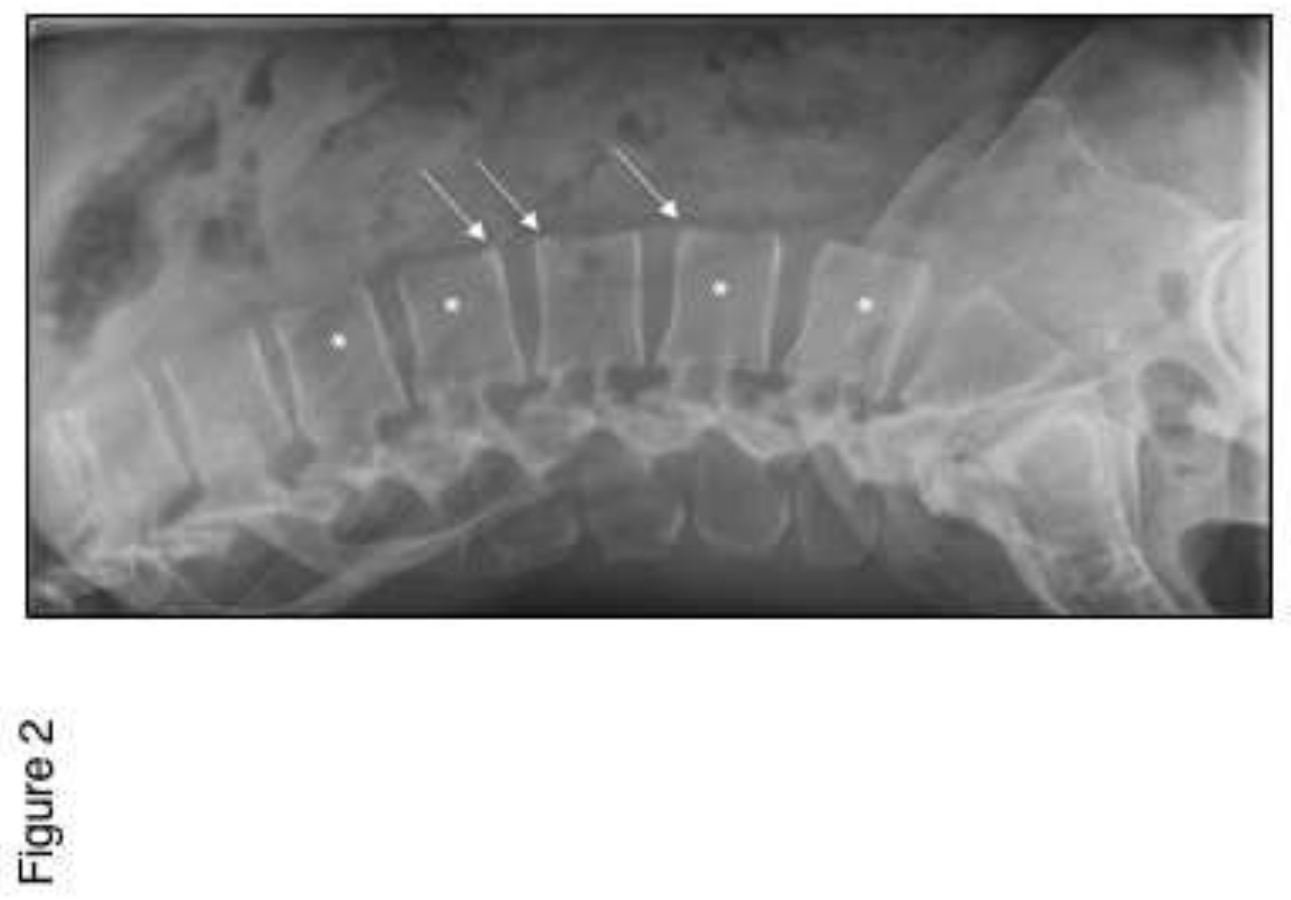

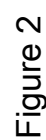




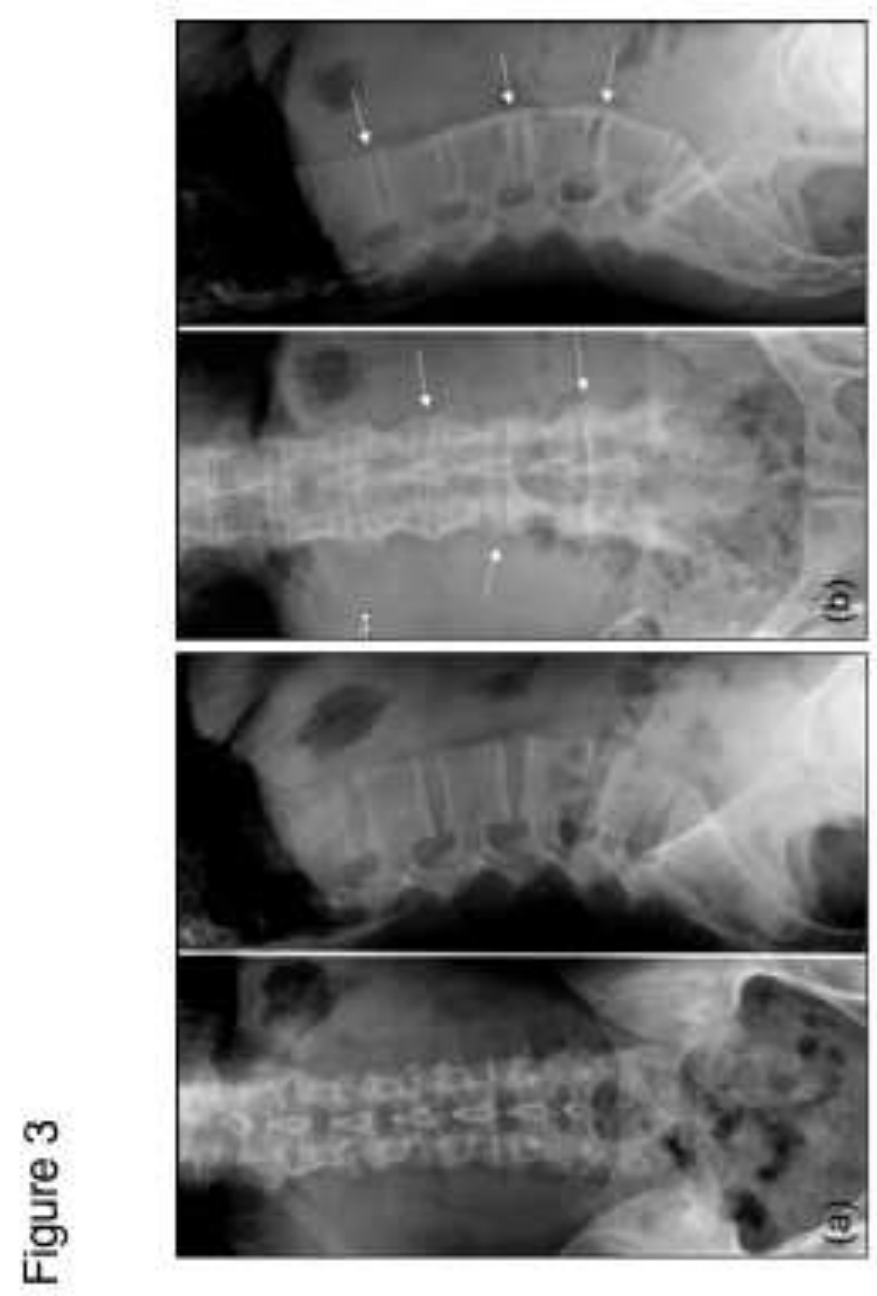

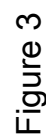




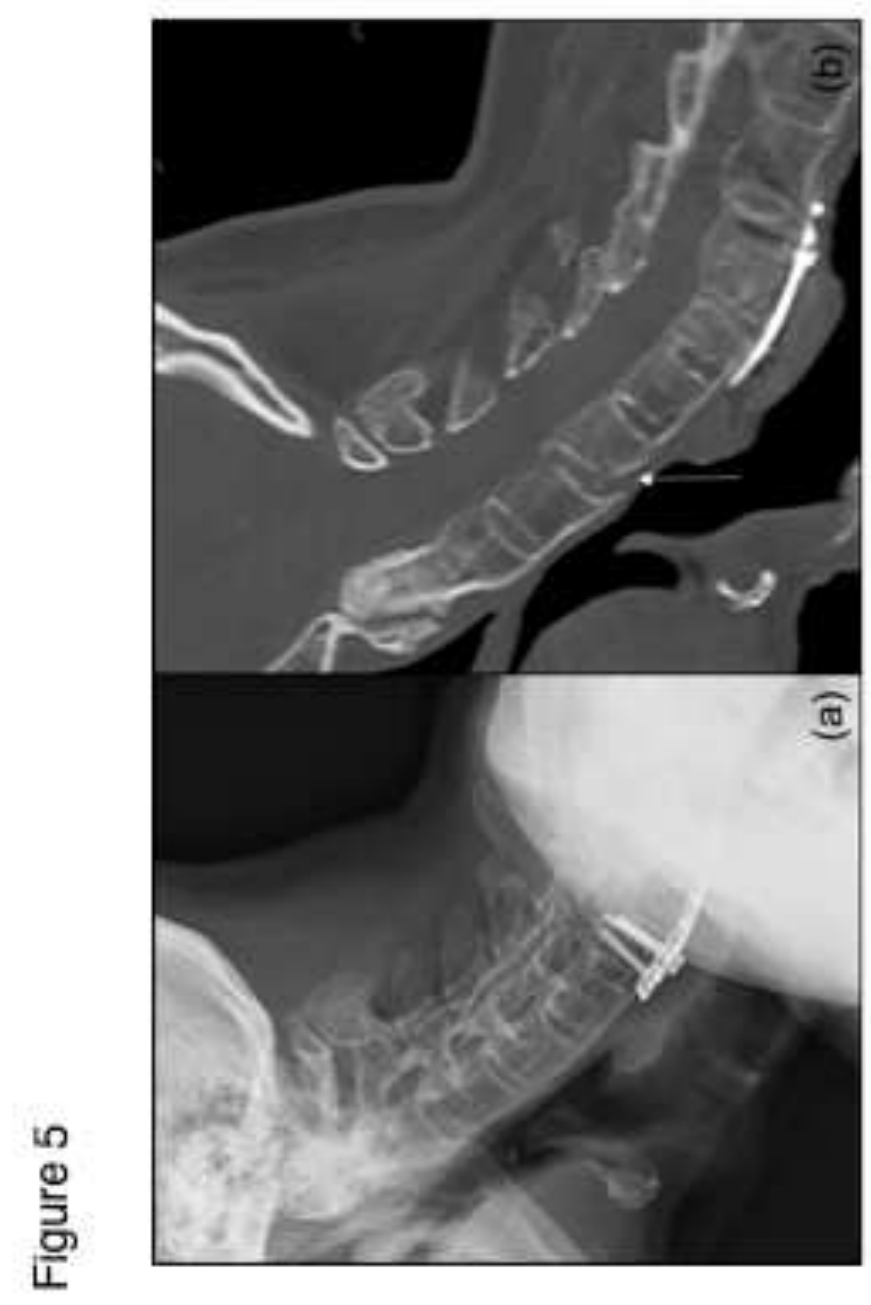

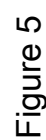




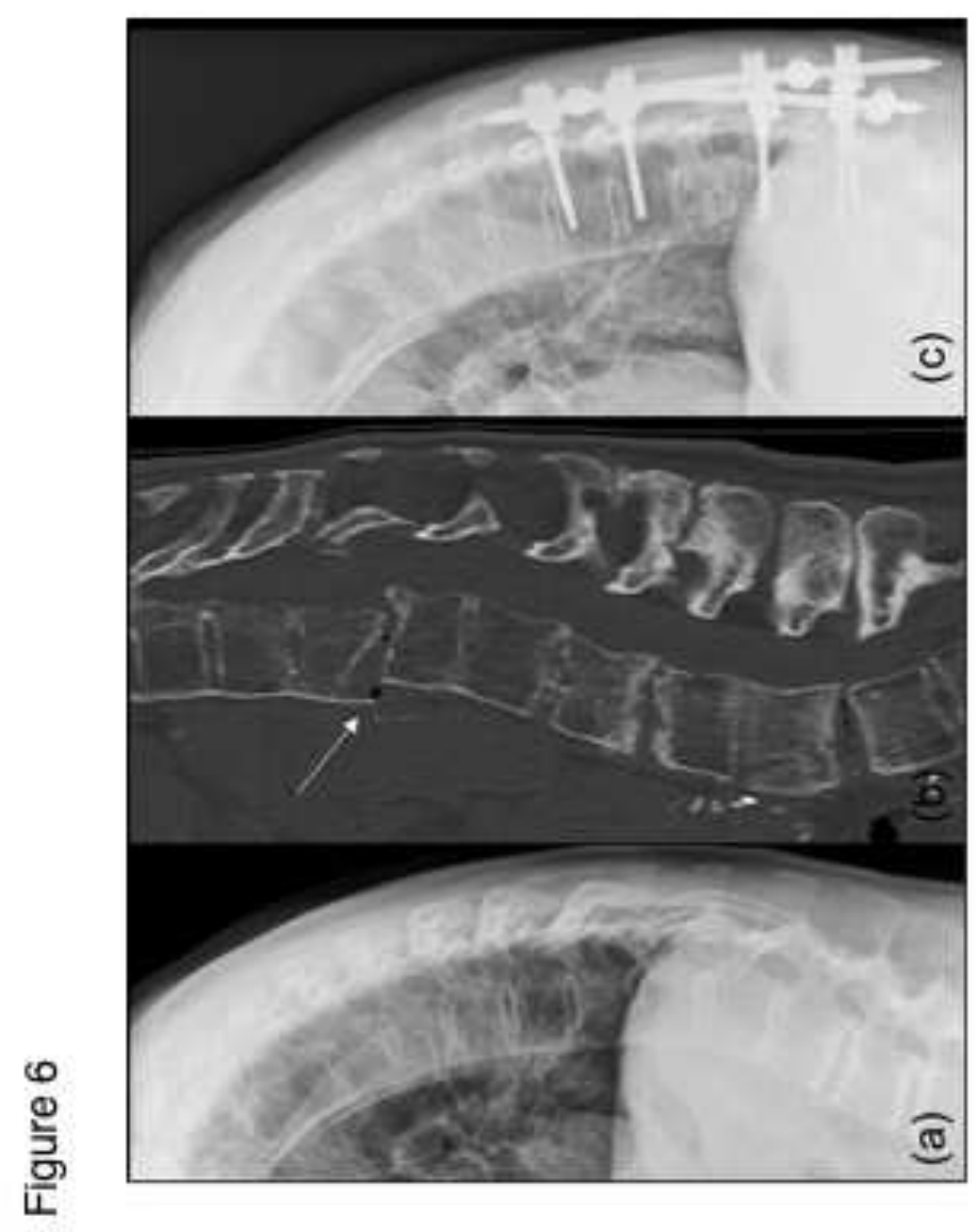

0
0
$\frac{1}{5}$
믄 


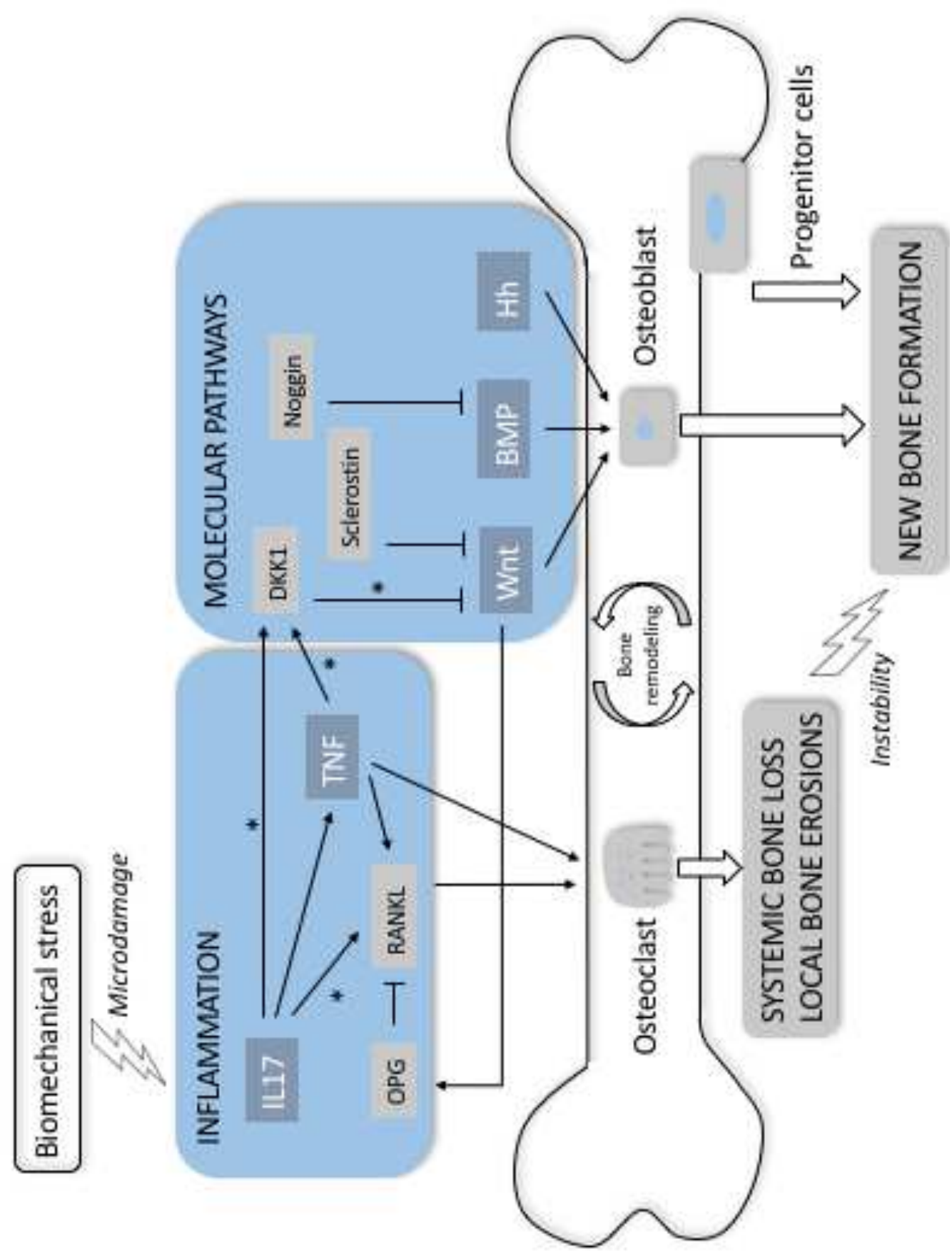

ํㅗㄱ 